\title{
Ultra-rare cystic disease
}

\author{
Davide Elia ${ }^{1}$, Olga Torre ${ }^{1}$, Roberto Cassandro ${ }^{1}$, Antonella Caminati ${ }^{1}$ and \\ Sergio Harari (iD ${ }^{1,2,3}$
}

\author{
Number 2 in the Series "Ultra-rare lung disease" \\ Edited by Sergio Harari and Marc Humbert
}

\begin{abstract}
Affiliations: ${ }^{1}$ U.O. di Pneumologia e Terapia Semi-Intensiva Respiratoria - Servizio di Fisiopatologia Respiratoria ed Emodinamica Polmonare, Ospedale San Giuseppe - MultiMedica IRCCS, Milan, Italy. ${ }^{2}$ Dept of Medical Sciences San Giuseppe Hospital MultiMedica IRCCS, Milan, Italy. ${ }^{3}$ Dept of Clinical Sciences and Community Health, University of Milan, Milan, Italy.
\end{abstract}

Correspondence: Roberto Cassandro. U.O. di Pneumologia e Terapia Semi-Intensiva Respiratoria - Servizio di Fisiopatologia Respiratoria ed Emodinamica Polmonare, Ospedale San Giuseppe - MultiMedica IRCCS, Via San Vittore 12, 20123 Milan, Italy. E-mail: roberto.cassandrolamultimedica.it

@ERSpublications

Diffuse cystic lung diseases show a characteristic CT scan pattern that often allows for diagnosis, even in asymptomatic patients, allowing prompt correct therapy and management without the needing of a biopsy https://bit.ly/2wIUKet

Cite this article as: Elia D, Torre O, Cassandro R, et al. Ultra-rare cystic disease. Eur Respir Rev 2020; 29: 190163 [https://doi.org/10.1183/16000617.0163-2019].

ABSTRACT Diffuse cystic lung diseases include a group of heterogeneous disorders characterised by the presence of cysts within the lung parenchyma, sometimes showing a characteristic computed tomography scan pattern that allows diagnosis. The pathogenetic mechanisms underlying cyst formation in the lung are still not clear and a number of hypotheses have been postulated according to the different aetiologies: ball-valve effect, ischaemic dilatation of small airways and alveoli related to infiltration and obstruction of small vessels and capillaries that supply the terminal bronchioles and connective tissue degradation by matrix metalloproteases. A wide number of lung cyst diseases have been classified into six diagnostic groups according to the aetiology: neoplastic, congenital/genetic, lymphoproliferative, infective, associated with interstitial lung diseases, and other causes. This article focuses on lymphangioleiomyomatosis, pulmonary Langerhans cell histiocytosis and Erdheim-Chester disease, Birt-Hogg-Dubé, follicular bronchiolitis and lymphocytic interstitial pneumonia, light-chain deposition disease and amyloidosis, congenital lung disease associated with aberrant lung development and growth, and cystic lung disease associated with neoplastic lesion. These cystic diseases are epidemiologically considered as ultra-rare conditions as they affect fewer than one individual per 50000 or fewer than 20 individuals per million. Despite the rarity of this group of disorders, the increasing use of high-resolution computed tomography has improved the diagnostic yield, even in asymptomatic patients allowing prompt and correct therapy and management without the need for a biopsy.

\section{Introduction}

On computed tomography (CT) scans, pulmonary cysts appear as a regular or irregular spherical parenchymal lucency with a well-defined interface within the lung [1]. Generally, they are filled with air, but occasionally may contain fluid or solid material. The increasing use of CT scans in recent decades has

Previous articles in the series: No. 1: Weatherald J, Dorfmüller P, Perros F, et al. Pulmonary capillary haemangiomatosis: a distinct entity? Eur Respir Rev 2020; 29: 190168.

Provenance: Commissioned article, peer reviewed

Received: 23 Nov 2019 | Accepted after revision: 20 March 2020

Copyright $\odot$ ERS 2020. This article is open access and distributed under the terms of the Creative Commons Attribution Non-Commercial Licence 4.0. 
improved knowledge in this field, allowing a better understanding of their development, progression and prognosis.

The mechanism underlying the pathogenesis of pulmonary cysts is still not well understood. Various hypotheses have been formulated, especially for lymphangioleiomyomatosis (LAM) and pulmonary Langerhans cell histiocytosis (PLCH) [2]. One of the mechanisms suggested for cyst formation is the ball-valve effect. The air is able to enter the small airways, but not to be exhaled, resulting in an expansion of the airways. This process occurs in the development of cysts in follicular bronchiolitis, in cystic tumours and pneumatoceles due to pulmonary infections $[3,4]$. It has even been hypothesised for LAM, PLCH and other diffuse cystic lung diseases (DCLDs), but in all these cases a communication within the airways and breath fluctuation may justify partial airflow in both directions [5].

Another suggested mechanism is the ischaemic dilatation of small airways and alveoli related to the infiltration and obstruction of small vessels and capillaries supplying the terminal bronchioles [6]. Connective tissue degradation by matrix metalloproteases leads to the development of cysts in several DCLDs, included LAM and PLCH $[2,7]$.

High-resolution computed tomography (HRCT) scans of the chest are the main diagnostic tool for DCLDs, although cysts are often confused with other air-filled structures in the lung, particularly cavities, blebs and bullae. The cavity walls show a thickness $>2 \mathrm{~mm}$ and present a more irregular shape compared to the cysts [8]. A bulla appears as a spherical lucency $>1 \mathrm{~cm}$ in diameter, is thin-walled and generally associated with emphysematous alterations in the remaining pulmonary parenchyma. Blebs are small cystic air spaces localised close to the visceral pleura, which are $<1 \mathrm{~cm}$ in size. Vessels and septa are occasionally observed in DCLDs, but not in LAM and PLCH. Other lung parenchymal alterations may be confused with cysts, for example bronchiectasis, although in this case airway dilatation and distortion can be correctly observed in continuous sections on a CT scan. Even emphysematous changes can mimic cystic lesions, but in this case, there is a very thin wall.

DCLDs include a group of heterogeneous disorders characterised by the presence of cysts within the lung parenchyma, sometimes showing a characteristic and diagnostic CT pattern. According to the pathophysiologic mechanisms, this group of diseases can be divided into neoplastic, congenital, genetic, lymphoproliferative, developmental, infectious, inflammatory or smoking-related disorders (table 1).

TABLE 1 Proposed classification of pulmonary cystic diseases

\begin{tabular}{ll} 
Classification & Diseases \\
\hline Neoplastic & Lymphangioleiomyomatosis \\
& Pulmonary Langerhans cell histiocytosis \\
& Erdheim-Chester disease \\
& Primary or metastatic tumours (mainly sarcomas, pulmonary \\
blastomal & Birt-Hogg-Dubé syndrome \\
Genetic/congenital & Neurofibromatosis \\
& Congenital pulmonary airway malformation \\
Associated with lymphoproliferative & Lymphocytic interstitial pneumonia \\
disorders & Follicular bronchiolitis \\
& Sjögren syndrome \\
& Amyloidosis \\
Infectious & Light-chain deposition disease \\
& Pneumocystis jiroveci \\
& Streptococcus pneumoniae \\
& Recurrent respiratory papillomatosis \\
Associated with ILD & Coccidioidomycosis \\
& Hypersensitive pneumonitis \\
& Desquamative interstitial pneumonia \\
Miscellaneous & Respiratory bronchiolitis \\
& Post-traumatic pseudocysts \\
& Fire-eater's lung \\
Hyper-lgE syndrome
\end{tabular}

ILD: interstitial lung disease; Ig: immunoglobin. Adapted with permission from the American Thoracic Society [9]. 
This review focuses on the clinical characteristics and the therapeutic approach in ultra-rare cystic diseases, affecting fewer than one individual per 50000 or fewer than 20 individuals per million [10].

\section{LAM}

LAM is a rare neoplastic disease almost exclusively affecting women in their reproductive age, characterised by the formation of lung cysts, abdominal tumours known as angiomyolipomas (AMLs), which usually involve the kidneys and lymphatic manifestations, including lymphangioleiomyomas [11]. The prevalence is estimated to be around one to nine people per million (www.orpha.net).

LAM can arise sporadically (S-LAM) or can be associated with the tuberous sclerosis complex (TSC), an autosomal dominant disorder characterised by hamartomatous lesions in several organs [12].

LAM is caused by mutations in the tuberous sclerosis TSC1 gene or, much more frequently, the TSC2 gene, with consequent loss of function of the proteins hamartin and tuberin, respectively [13, 14]. Inactivating mutations of TSC1 and TSC2 genes result in constitutive activation of the mammalian/mechanistic target of rapamycin (mTOR) pathway, whose major function is the regulation of cell growth and proliferation [11].

Different mechanisms have been hypothesised to be involved in the formation of lung cysts, as previously described [2].

The most common respiratory manifestations of LAM are dyspnoea ( $>70 \%$ of cases), pneumothorax, which is often recurrent and bilateral, and chylous pleural effusions [15-17].

Although almost $30 \%$ of patients with LAM have normal lung function, the most frequent pulmonary function abnormalities are airflow obstruction and decreased diffusing capacity of the lung for carbon monoxide (DLCO) $[16,18-20]$. DLCO and forced expiratory volume in $1 \mathrm{~s}$ (FEV1) have been reported to correlate with disease severity as assessed by CT, histology score and exercise testing [21-23]. The rate of decline in lung function in untreated patients is variable and often unpredictable. In different retrospective studies the mean annual decline in FEV1 ( $\Delta$ FEV1) has been reported as $60-120 \mathrm{~mL}$ per year [24-26]. The mean $\triangle \mathrm{FEV} 1$ post-bronchodilator in the placebo group of the Multicenter International Lymphangioleiomyomatosis Efficacy of Sirolimus (MILES) trial and in the trial with doxycycline (two randomised, placebo-controlled trials) were $-134 \mathrm{~mL}$ (in the 12 month study period) and $-90.3 \mathrm{~mL}$ per year, respectively $[27,28]$.

Extrapulmonary manifestations of LAM include abdominal haemorrhage or effusions or the detection of an abdominal mass due to AML, lymphangioleiomyoma or lymphadenopathy [16, 29, 30]. AMLs are benign tumours that mainly occur in the kidneys. They can be present in up to $50 \%$ of patients with S-LAM; patients with TSC-LAM usually have multiple and larger AML [16, 31-33]. AMLs can be asymptomatic, but the large ones can cause bleeding and acute symptoms [34]. AMLs usually have a characteristic CT appearance because of the presence of fat, or can be clearly recognised by magnetic resonance imaging (MRI) [35].

Lymphangioleiomyomas are cystic tumours occurring primarily in the retroperitoneum along the axial lymphatics and have been reported in up to $10 \%$ of patients [35]. Lymphangioleiomyomas may be asymptomatic or present with abdominal distension, peripheral oedema, urinary symptoms, or as an acute abdomen [36-38]. They usually have a distinctive radiological appearance on CT or MRI; changes of lymphangioleiomyoma volume during the day have been described $[22,30]$.

Chest radiography often appears normal in the early stages of the disease except in the presence of pneumothorax or pleural effusions. In a more advanced phase of disease a reticulonodular pattern is the most common findings [11]. The characteristic abnormality on lung HRCT is the presence of well circumscribed, round and thin-walled cysts that are disseminated in a bilateral symmetric pattern, also involving the basis of the lung parenchyma; the size of the cysts can range from a few millimetres to several centimetres (figure 1a) [22, 30, 39].

A definite diagnosis of LAM can be obtained in the presence of the characteristic changes on HRCT and with any of the following criteria: TSC, AMLs, chylous pleural effusions or ascites, and cystic lymphangioleiomyomas, or biopsy-proven involvement of lymph nodes [40].

More recently, levels of vascular endothelial growth factor-D (VEGF-D) have also been recognised as diagnostic criteria. Levels of VEGF-D, a lymphangiogenic growth factor involved in the development of lymphatic vessels and the spread of tumour cells to lymph nodes, were shown to be higher than those detected in healthy controls [41, 42]. Moreover, serum VEGF-D levels were also found to be higher in LAM patients than in healthy volunteers and in patients with other cystic or chylous lung diseases. VEGF-D levels were also higher in women with TSC and LAM than in women with TSC with no evidence of cystic changes on CT scans [43]. 

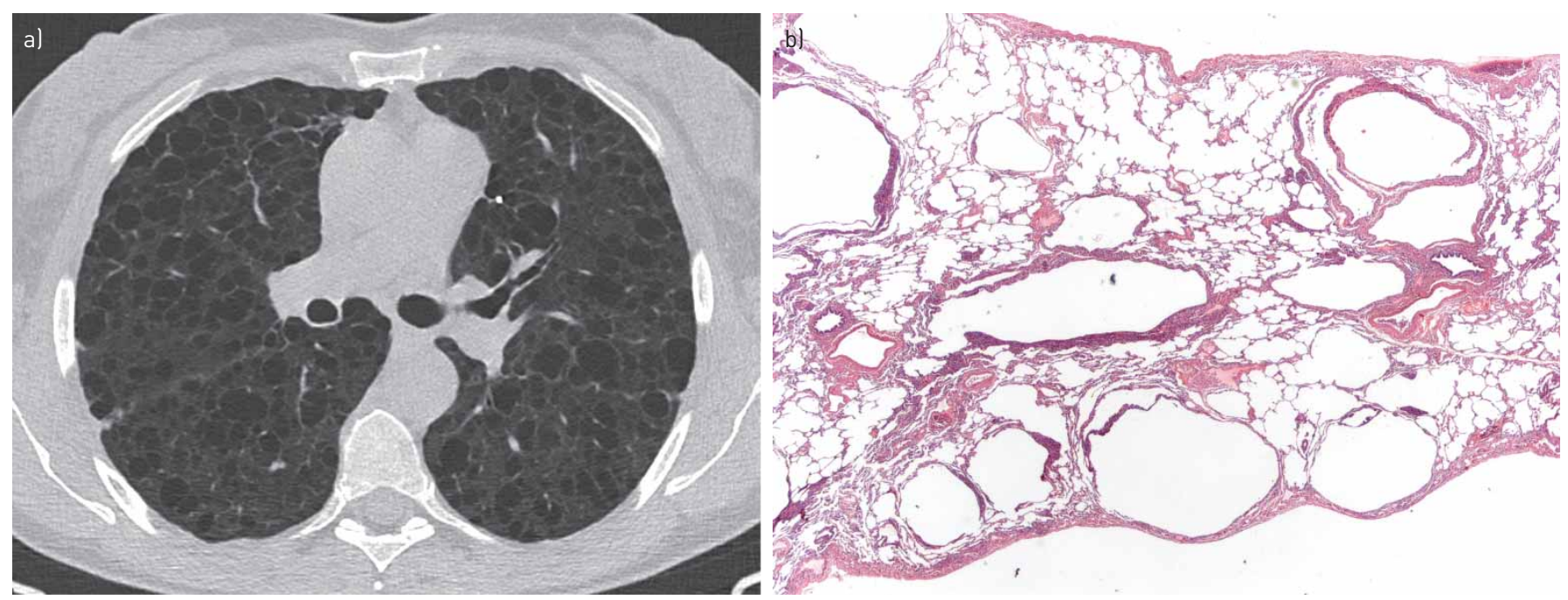

FIGURE 1 a) High-resolution computed tomography scan of the chest in a patient with lymphangioleiomyomatosis (LAM). Round, thin-walled round cysts are distributed diffusely throughout the lungs. The patient underwent right pleurodesis for pneumothorax. b) Surgical lung biopsy showing several thin-walled cysts of varying dimensions with small plaques of LAM cells in the wall of the cysts (arrows) (Haematoxylin and Eosin stain, 20x). Figure was provided courtesy of A. Cavazza (Unit of Pathologic Anathomy, Azienda Arcispedale S, Maria Nuova/IRCSS, Reggio Emilia, Italy).

In a prospective study on 48 patients with cystic lung disease of unknown aetiology serum VEGF-D levels $>800$ pg. $\mathrm{mL}^{-1}$ could identify LAM with a sensitivity and specificity of $73 \%$ and $100 \%$, respectively [44]. A subsequent study showed that serum VEGF-D levels could identify LAM with a sensitivity and specificity of $87 \%$ and $90 \%$, respectively, using a diagnostic threshold of $468 \mathrm{pg} \cdot \mathrm{mL}^{-1}$ [45]. Based on these results, VEGF-D testing for noninvasive diagnostic confirmation of LAM in cases with characteristic HRCT, is recommended, when other confirmatory criteria are lacking [46].

Lung biopsy should still be considered when confirmatory features are lacking or if VEGF-D levels are $<800 \mathrm{pg} \cdot \mathrm{mL}^{-1}$ [47]. Transbronchial lung biopsy can be performed before considering surgical lung biopsy $[47,48]$.

LAM lesions are characterised by the presence of LAM cells which are peculiar cells co-expressing myogenic markers, such as $\alpha$-actin and desmin, and melanocytic markers, such as gp100 and MelanA/ Mart1; for this reason LAM has been included in the family of "perivascular epithelioid cell tumours" [2]. LAM cells also express receptors of progesterone and oestrogen. CD44v6, a glycoprotein that binds hyaluronic acid and is associated with metastatic cancers, has also been shown on the LAM cell surface [49]. LAM nodules or small cell clusters of LAM cells in the lungs can be detected near cystic lesions and along pulmonary bronchioles, blood vessels and lymphatics (figure 1b).

Serum VEGF-D might also be useful as a marker of disease severity and response to therapy: a data analysis of the MILES trial showed that median serum VEGF-D levels were reduced in the sirolimus group, but remained stable in the placebo group over the treatment period; moreover, higher VEGF-D levels at baseline were associated with enhanced improvement in lung function in the sirolimus group and faster lung function decline in the placebo group [40]. A retrospective study showed that serum VEGF-D levels $>800 \mathrm{pg} \cdot \mathrm{mL}^{-1}$ were associated with a faster rate of decline [50] in forced vital capacity (FVC) and a faster rate of increase in total lung capacity and residual volume, compared to patients with serum VEGF-D levels $<800 \mathrm{pg} \cdot \mathrm{mL}^{-1}$ [51]. Finally, serum VEGF-D levels can be related to clinical manifestations of LAM, with higher levels observed in patients with lymphatic disease, suggesting that serum VEGF-D levels might be a measure of lymphatic involvement in patients with LAM [42, 52].

Recent studies showed that LAM probably has a slower progression than previously reported, even if the disease course varies and the clinical outcomes can be difficult to predict.

Previous studies reported a mortality of $30 \%$ at 10 years from the time of lung biopsy [53] and 10-20\% from the onset of symptoms $[24,29,53]$.

A more recent study on a large cohort of patients $(n=401)$ with long-term follow-up showed an estimated 10-year transplant-free survival of $86 \%$ [54]. Finally, the results of the National Institutes of Health LAM Registry on the natural history of the disease have been published, showing an estimated 10- and 20-year transplant-free-survival of $85 \%$ and $64 \%$, respectively [55]. 
Recent studies, as reported in the following sections, show that the advent of sirolimus has changed the natural history of the disease.

Sirolimus, an inhibitor of mTOR, has been proven to be effective in the stabilisation of lung function (expressed as FEV1) during the 12-month treatment period in the MILES trial, a large randomised placebo-controlled trial on the safety and efficacy of sirolimus in patients with LAM and moderate functional impairment [27]. After discontinuation of treatment, the decline in lung function in the sirolimus group resumed and paralleled that in the placebo group. Moreover, during the treatment period, the sirolimus group showed improvement in FVC and quality of life and reduction of serum VEGF-D levels. Most common adverse events were mucositis, gastrointestinal events, hypercholesterolaemia, acneiform rash and swelling in the lower extremities. However, the rates of serious adverse events were similar in the treatment and placebo arms [27].

Sirolimus was also shown to be effective in controlling other manifestations of the disease such as AMLs and lymphatic disease [56-59]. The American Thoracic Society/Japanese Respiratory Society guidelines recommend sirolimus for patients with moderate lung function impairment or deteriorating lung function; they also suggest treatment with sirolimus for symptomatic chylous fluid accumulations, before invasive management [46]. To date, sirolimus is the only therapy which has been approved for patients with LAM by the US Food and Drug Administration (in 2015) and European Medicines Agency (in 2018).

In a recent prospective study on a cohort of 47 patients with a mean follow-up of 35.8 months, regardless of an overall stability of the lung function, 12 patients experienced a continuous decrease in FEV1 [60]. The authors suggest that the variability over time in the response to treatment may be due either to different disease phenotypes or to an acquired resistance to sirolimus.

In the past, various hormonal treatments have been adopted for LAM, including oophorectomy, anti-oestrogen therapy, gonadotrophin-releasing hormone analogues and progesterone [21, 25, 61-65]. Recently a randomised, controlled trial comparing the aromatase inhibitor letrozole versus placebo in post-menopausal women with LAM failed to show results because the target enrolment of 25 patients per arm was not met [66].

Due to the inconclusive results and the lack of controlled clinical trials, hormonal treatment is not recommended [46].

As matrix metalloproteinases (MMPs) are involved in pathogenesis of the disease, inhibition of MMPs is considered a potential target in the treatment of LAM. A case of significant clinical improvement in association with the reduction of urinary levels of MMPs after treatment with doxycycline, an inhibitor of MMPs, was reported by Moses et al. [67]. In a double-blind, placebo-controlled clinical trial of doxycycline, the mean $\triangle \mathrm{FEV} 1$ did not differ between the active treatment and the placebo groups, although the effect on urinary levels of MMP-9 was confirmed [28].

The observation of potential drug resistance with sirolimus and recent advances in understanding the pathogenesis of the disease suggested new potential targets.

The inhibition of autophagy in combination with mTOR inhibition has been shown to be more effective than either treatment alone, both in vitro and in animal models [68]. In a recently published phase I clinical trial on the safety and tolerability of sirolimus in combination with hydroxychloroquine in patients with LAM mucositis, headache and diarrhoea were the most commonly reported adverse events; no serious drug-related adverse events were observed [69]. The analysis of secondary end-points showed an improvement in FEV1 and FVC after 24 weeks of treatment, both of which remained stable at 24 months of the observation when the higher dose of hydroxychloroquine (400 $\mathrm{mg}$ daily) was analysed separately.

Various intracellular kinases are also supposed to be involved in the pathogenesis of LAM, while different studies on inhibitors targeting these molecules, such as saracatinib, nintedanib and imatinib are currently underway.

Lung transplantation is a reliable therapeutic option for end-stage pulmonary LAM. A recent study on the outcome of 138 LAM patients who underwent transplant in the USA showed a 10-year survival of 56\%, which was significantly higher than in other lung diseases (32\%): this advantage persisted after age- and sex-matched analysis [70]. Positive outcomes were also reported by two retrospective studies in a German and a Japanese centre even if the latter found a high rate of LAM-related complications in long-term follow-up (e.g. chylothorax, pneumothorax and LAM recurrence) [71, 72].

Large asymptomatic AML at an increased bleeding risk should be closely and frequently followed-up by CT or MRI [40]. Bleeding AMLs should be treated as conservatively as possible to preserve renal function; nephron-sparing surgery and embolisation have been performed safely [40,73]. 
Pneumothorax is a frequent complication of LAM. It can be treated conservatively at the first episode. However, considering the high recurrence rate of pneumothorax, an early interventional treatment with pleurodesis could be considered, thus decreasing morbidity, disease burden and cost [48].

\section{PLCH and Erdheim-Chester disease}

Langerhans cell histiocytosis (LCH) and Erdheim-Chester disease (ECD) are histiocytic neoplasms, a group of diseases characterised by the accumulation of specific cells, thought to be derived from dendritic cells or macrophages. The rigid distinction between Langerhans and non-Langerhans cell groups, suggested by the Working Group of Histiocytosis [74], has been changed in the last classification [75] and now LCH and ECD share the same group. In fact, it has been found that around $20 \%$ of patients with ECD also show LCH lesions [76]; furthermore, clonal mutations involving genes of the mitogen-activated protein kinase (MAPK) pathway have been observed in $80 \%$ of cases in both diseases [77-80] particularly the proto-oncogene BRAF-V600E and blood monocytes harbouring the same mutations [81-83]. The prevalence is around one to two cases per 100000 and the disease is generally diagnosed during childhood (www.orpha.net).

$\mathrm{LCH}$ has been classified according to the number of organs involved in systemic or in single-organ manifestation. The systemic form is associated with a worse prognosis, especially when the so-called risk organs (liver, spleen and haematopoietic organs) are involved. Bones, skin and lungs are the main sites of single manifestations and are generally characterised by a better prognosis [84]. Although pulmonary involvement may be observed in the systemic form, both in children and adults [84, 85], it generally occurs in young adults, smokers or ex-smokers in $>90 \%$ of cases (PLCH). As the disease is often asymptomatic the exact prevalence among adults is unknown; however, the incidence is estimated to be around one to two cases per million adults per year (www.orpha.net). In the case of ECD, the exact prevalence is unknown due to the rarity of the disease. In the UK, less than 500 cases have been reported. In ECD the main sites involved are bones, but potentially every organ and tissue may be affected. In $50 \%$ of cases [86] a respiratory system involvement has been observed.

Respiratory symptoms are not specific in PLCH and in ECD but are more frequent in the former case. In fact, PLCH patients may complain of a cough (50-70\%), dyspnoea (40-80\%) and chest pain (10-21\%), sometimes associated with fatigue, weight loss and fever. However, in $15-20 \%$ of cases, PLCH is diagnosed following an episode of spontaneous pneumothorax or as an incidental finding during a routine chest radiograph. Sometimes, the earliest symptoms may be related to extra-thoracic localisation of the disease, such as polyuria-polydipsia syndrome due to diabetes insipidus as a consequence of hypothalamic localisation (20-30\% of patients) [87] or the presence of osteolytic lesions which may lead to spontaneous bone fractures. At the time of diagnosis, bone pain and neurological alterations are the most frequent symptoms referred by patients, related to bone involvement. A worse prognosis is associated with pulmonary involvement in ECD and it is more frequent in subjects aged $>70$ years $[88,89]$. In $25-50 \%$ of cases diabetes insipidus is diagnosed in ECD patients. In addition to exophthalmos, which has been reported in $30 \%$ of cases [90] (with or without altered vision due to periorbital involvement and cell accumulation in this area), xanthomas of the eyelid have been frequently described (25\%). Common symptoms related to neurological involvement are altered vision, excessive thirst or urination, ataxia, headache, weakness, and signs of cord compression. A common complaint reported in $55-85 \%$ of the cases of ECD is the presence of a periarterial fibrosis of the thoracic and abdominal aorta due to histiocytic infiltration in the adventitia.

CT imaging is very helpful in both diseases and can be observed with a characteristic pattern. In PLCH, lung lesions can vary during the course of the disease and a combination of nodules, cavitations of nodular lesions measuring $1-10 \mathrm{~mm}$ in diameter and thick- or thin-walled cysts, that may coalesce to form irregular shapes, are typical findings. All these lesions are localised in the upper and middle lung regions, sparing the lower lung areas and the costophrenic angles of the lung. Less frequently, the concomitant presence of other smoking-related interstitial lung diseases may be found while extensive ground-glass opacities are observed on the CT (figure 2) [91, 92]. A predominant upper-lung quadrant cyst localisation has been described in ECD; however, multiple small, rounded, thin-walled cysts with a random distribution have been observed [93, 94]. Diffuse small centrilobular or ground-glass opacities generally localised in the upper lung areas and plural effusion are less frequently reported.

In the presence of a characteristic radiological pattern, bronchoscopy is not required for the diagnosis of pulmonary involvement in this group of diseases, even though it is useful to exclude alternative diagnoses and/or infections. The presence of at least $5 \%$ of $\mathrm{CD}^{+} \mathrm{a}^{+}$dendritic cells in the bronchoalveolar lavage associated with a typical radiological pattern, supports the diagnosis of PLCH, although this was only observed in a few cases $[48,95]$. Sample collection may be useful but, due to the focal nature of the lesions, transbronchial lung biopsies are not recommended. Cryobiopsy may have a higher diagnostic yield as the specimens collected are bigger in size $[96,97]$. 

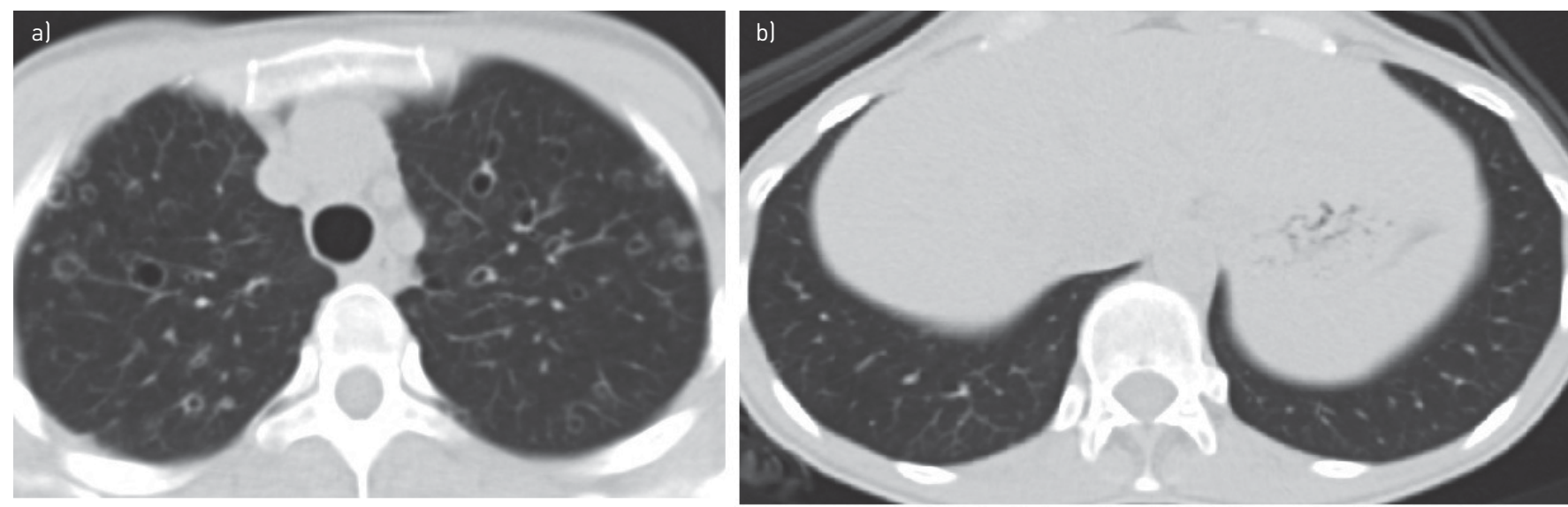

FIGURE 2 High-resolution computed tomography scans of the chest in a patient with pulmonary Langerhans cell histiocytosis with a combination of small nodules, cavitary nodules and lung cyst in al the upper lobe and b) lower/angle costophrenic sparing.

Histologically, PLCH is characterised by the presence of $\mathrm{CD}^{+}{ }^{+}$cells organised into loosely aggregated granulomas. A convoluted and irregularly indented nucleus, pale, slightly eosinophilic cytoplasm, with positivity for CD1a and langerin (CD207) on immunohistochemical examination is observed in Langerhans cells. During the course of the disease, the inflammatory cells persist and are associated with lymphoid aggregates, although the amount of $\mathrm{CD}^{+}$cells tends to decrease. With the progression of the disease, inflammatory cells are replaced by fibrotic tissue, forming the characteristic stellate scarring or by a fibrous ring surrounding the cyst [98]. The presence of $\mathrm{CD}^{+} 8^{+}, \mathrm{CD}_{163}{ }^{+}$, Factor XIIIa ${ }^{+}, \mathrm{CD} 1 \mathrm{a}-, \mathrm{S} 100-/$ low, langerin foamy or lipid-laden histiocytes is the characteristic immunohistochemical pattern in detecting histological changes in different tissues [86]. Both in PLCH and ECD, detection of BRAFV600E expression and other MAPK-extracellular signal-regulated kinase pathway mutations, included NRAS and KRAS [99] by means of immunohistochemistry is a simple and effective screening method for tailored treatment.

Treatment approach can vary, according to the extent and severity of each disease. In PLCH, due to its link with smoking habits, smoking cessation may be the only intervention required in a number of patients. The effect of smoking cessation on extra-pulmonary manifestations of the disease is not clear $[100,101]$ and there is no relationship between ECD and smoking. In patients affected by PLCH, in case of disease progression despite smoking cessation, corticosteroids or other chemotherapeutic drugs should be considered, although no trial demonstrates the effect of steroids on reducing the decline of lung function. Vinblastine has been used in LCH with multi-systemic manifestation, but its efficacy on pulmonary involvement is limited. In PLCH, an improvement in lung function, a reduction in the volume of cysts and, in selected patients, a complete resolution of the disease has been reported with the use of cladribine in monotherapy [102-104]. In a retrospective analysis in ECD, a partial clinical response has been observed [105].

In ECD the use of pegylated interferon- $\alpha$ showed a significant improvement in overall survival compared to steroids or other immunosuppressors; however, frequent treatment interruption due to psychological side-effects (mainly depression) have been reported [106-108].

In the past few years, the increasing identification of gene mutation in the MAPK pathways both in LCH, PLCH and ECD allowed the use of new drugs in selected patients harbouring these mutations. A BRAF inhibitor, vemurafenib, led to stabilisation of disease in a subset of patients affected by systemic LCH [109] and a general improvement in symptoms; a persistent response has been demonstrated in ECD patients treated with vemurafenib, while the US Food and Drug Administration has recently approved the therapy for this subgroup. Severe cutaneous adverse events and the development of skin tumours (squamous cell carcinoma) have been reported [110]. Recently, trametinib, a MEK1 and 2 kinase inhibitor, down-streaming BRAF in MAPK pathways, have been successfully used in one patient affected by PLCH [111].

Furthermore, in a phase II trial, 18 patients (12 with ECD, 2 with LCH, 2 with Rosai Dorfman disease and 2 with mixesd histiocytosis) were treated with cobimetinib, another MEK $1 / 2$ inhibitor, and after 1 year of treatment, $72 \%$ showed a complete response, evaluated by means of 2-fluoro-2-deoxy-D-glucose positron emission tomography, while a partial response was observed in $17 \%$. A stabilisation of the disease was reached in $6 \%$ of cases [112].

Encouraging survival data after lung transplantation in PLCH supports the idea of taking this approach into consideration in patients with an advanced form of the disease. However, in patients who resumed smoking after transplantation, a relapse of the disease has been recorded [113]. 
Pulmonary hypertension may be a complication in PLCH and its pathogenesis is still debated [114,115]. The use of specific treatments in retrospective analysis (including endothelial receptor antagonist, 5-phosphodiesterase inhibitors and inhaled iloprost) has led to improved haemodynamic function without worsening gas exchanges or inducing pulmonary oedema. An improvement in dyspnoea scores and haemodynamic parameters has been observed in other small case series $[116,117]$.

A complete haematological work-up should be recommended due to the neoplastic nature of both diseases.

\section{Birt-Hogg-Dubé}

Birt-Hogg-Dubé (BHD) syndrome is a rare autosomal dominant inherited disorder caused by mutations in the folliculin $(F L C N)$ gene. It is characterised by pulmonary cysts, skin involvement and early onset of renal benign tumours or malignancies.

BHD is caused by mutations in the gene encoding for the tumour suppressor protein folliculin that is highly expressed in kidneys, lungs and skin [118]. The exact mechanism of tumours and lung cyst formation in BHD is still unclear. Different pathways have been implicated in the tumour-suppressive effect of FLCN, including the mTOR pathway, transforming growth factor- $\beta$ signalling and the "differentially expressed in normal cells and neoplasia" proteins that regulate intracellular trafficking [119123]. More recently, FLCN-dependent defects in WNT pathway developmental cues have been suggested to contribute to lung cyst pathogenesis [124].

BHD usually manifests itself in the third to fifth decade of life with no sex predilection [125-127], even if there have been reports of the disease in patients aged $<20$ years and $>80$ years [128]. Patients with BHD can present different combinations of pulmonary, lung and renal manifestations.

Pulmonary cysts have been found on chest HRCT scans in $>80 \%$ of adult patients with the disease [129]; in some cases, pulmonary cysts can be found in the absence of skin or renal involvement [127]. The presence of pulmonary cysts predisposes to spontaneous and frequently recurrent (75\% of cases) pneumothorax whose incidence in patients with BHD is about 50-fold higher than in general population [125, 129-131]. The recurrence rate of pneumothorax is significantly reduced after surgical treatment [132]. Moreover, pneumothorax has been described in BHD in the absence of cysts on CT scan [133]. Recent studies showed that BHD syndrome is one of the most common causes of familial spontaneous pneumothorax [134, 135]; thus, a family history of spontaneous pneumothorax should promptly suggest an evaluation for BHD by means of imaging modalities and genetic testing in order to guarantee an early diagnosis of the disease.

On HRCT scan, cysts predominantly have a basilar and peripheral location, round to lentiform shape with a wide size range (from a few millimetres to several centimetres) and a thin wall (figure 3). Compared to LAM, cysts in patients with BHD have been found to have a more irregular shape, more septation, lower and subpleural distribution, larger maximum size, and indentation on mediastinal fat [136, 137]. In lung tissue, the cysts are surrounded by normal lung parenchyma and no evidence of inflammation, neoplastic proliferation or fibrosis [120]. They frequently abut into the interlobular septa and sometimes contain internal septa consisting of interlobular septa (figure 4) [120, 138].
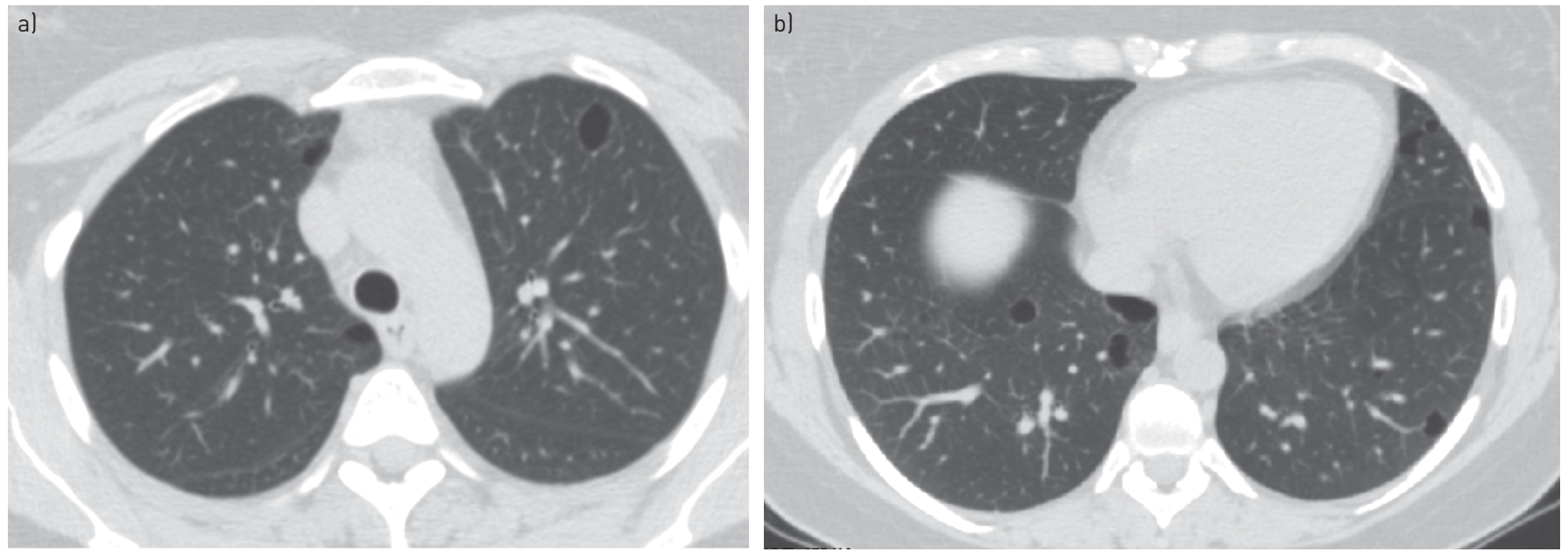

FIGURE 3 High-resolution computed tomography scans of the chest in a patient with Birt-Hogg-Dubé. Round and lenticular shaped thin-walled cysts with a prevalent lower and subpleural distribution can be seen in a) the upper lobes and b) lower lobes. 
FIGURE 4 Surgical lung biopsy of a patient with Birt-Hogg-Dubé showing large thin-wall lung cysts surrounded by normal lung parenchyma with no evidence of lymphangioleiomyomatosis cells or signs of inflammation or tumour (Haematoxylin and Eosin, 20x). Figure was provided courtesy of A. Cavazza.

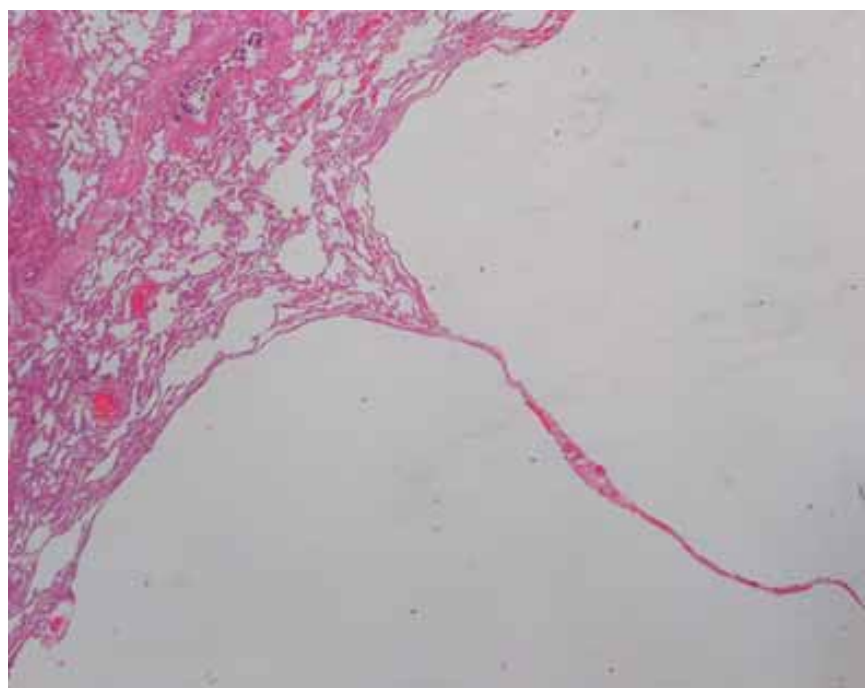

Skin lesions are the most common manifestations in patients affected by BHD, who typically develop facial papules, consisting of fibrofolliculomas or trichodiscomas (figure 5) [118, 140]. Renal lesions can range from benign oncocytomas to malignancies such as clear cell, papillary and mixed pattern carcinomas; they are often multifocal and bilateral and have been found at an earlier age than compared with the general population [129, 139-141]. However, a recent study including 178 patients from 50 families with BHD revealed that most kidney malignancies occurred after the age of 50 years [142]. In this study a possible genotype-phenotype correlation for kidney tumours has also been suggested. To date, no specific therapy for BHD syndrome is available. Individual and family genetic testing for FLCN should be offered in case of clinical suspicion of BHD. Usually, lung function is preserved or only mildly compromised [135, 136], even if data on the natural history of lung involvement are lacking. Interventional treatment for pneumothorax should be considered at the first episode because of the risk of a high recurrence rate. Given the high penetrance of renal tumours, screening for renal tumours should be recommended at regular intervals, once the diagnosis is established; MRI study of the abdomen may represent the best tool for serial screening $[141,142]$. Renal tumours are often oncocytoma and can be followed-up or treated with conservative surgery.

\section{Lymphocytic interstitial pneumonia and follicular bronchiolitis}

Lymphocytic interstitial pneumonia (LIP) refers to a rare pathological condition with diffuse involvement of the lung parenchyma by reactive pulmonary lymphoid tissues [143]. Follicular bronchiolitis (FB) is characterised by lymphoid follicular hyperplasia centred on the airway, vessels, and interlobular septa with a lymphatic distribution [144]. These clinicopathological entities may be idiopathic or associated with autoimmune diseases like Sjögren syndrome, rheumatoid arthritis, systemic lupus erythematous, or with human immunodeficiency states such as common variable immune deficiency and HIV infection [145, 146].

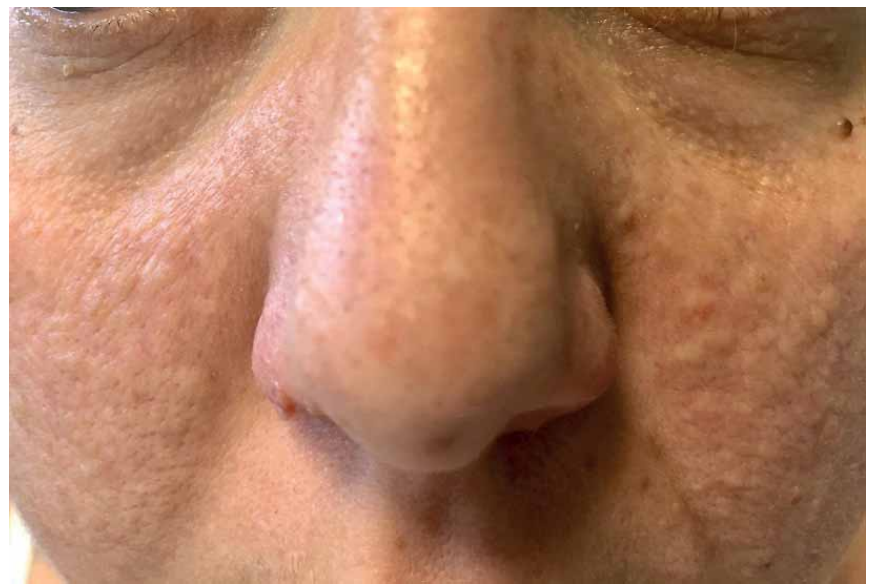


Recently a case of LIP in a patient with mixed connective tissue disease has been reported [147]. Sjögren syndrome is the connective tissue disorder most commonly associated with LIP/FB. Cysts in LIP/ FB may be due to ischaemia caused by vascular obstruction, post-obstructive bronchiolar ectasia, or bronchiolar compression by lymphoid tissues [145]. On HRCT, cysts have been described in up to $88 \%$ of patients with LIP $[148,149]$. They are usually fewer in number than in LAM and have a diameter $<30 \mathrm{~mm}$, may contain an internal structure or be bordered by eccentric vessels, and are randomly distributed [148]. In patients with Sjögren syndrome cyst size may range 3-52 $\mathrm{mm}$ [150]. In a recent review of CT images obtained from 14 patients with LIP, 16 patients with BHD and 17 patients with LAM, lower lung lobe predominant cysts were significantly more frequent in BHD (100\% of cases) and LIP (71-93\% of cases) than in LAM; paramediastinal and elliptical cysts were less likely to be found in LIP and LAM compared to BHD [147, 151]. In LIP/FB cysts are usually combined with centrilobular nodules, ground-glass opacities, or septal thickening $[152,153]$. Patients with LIP/FB may present progressive dyspnoea and/or cough. Pulmonary function tests of patients with LIP and FB usually show, a restrictive and an obstructive pattern, respectively. Reduction in DLCO may be a common finding [145, 154]. Although a cystic pattern on HRCT in patients with autoimmune connective disease can be sufficiently characteristic, in some cases lung biopsy is needed. Surgical lung biopsy has the best diagnostic yield to establish the diagnosis [145]. A differential diagnosis with mucosal-associated lymphoid tissue (MALT) lymphoma should be considered in case of increasing ground-glass opacities or consolidations on CT scan. After a histopathological diagnosis of LIP/FB, an evaluation for autoimmune and immunodeficiency conditions should be undertaken.

Stabilisation or improvement of the disease with corticosteroids, either alone or in combination with steroid-sparing agents, has been described in patients with interstitial abnormalities due to LIP [145]. Successful treatment has been reported with the use of antiretroviral drugs in patients with LIP secondary to HIV infection [155]. However, the cystic changes of LIP/FB may be refractory to treatment despite improvement in interstitial changes $[156,157]$.

\section{Light-chain deposition disease and amyloidosis}

Light-chain deposition disease (LCDD) is characterised by deposition of nonfibrillary, amorphous material composed of monotypic $\kappa$ light chains. Systemic LCDD is usually associated with lymphoproliferative disorders and is primarily characterised by renal involvement [158], while LCDD presenting itself as an isolated cystic lung disease is an extremely rare condition. HRCT findings varying from multiple small, round cysts to larger cystic spaces associated with reticulonodular opacities have been described [159]. Histologically, LCDD is characterised by monotypic $\kappa$ light-chain deposition in the small airways, alveolar walls and vessels, accompanied by emphysematous changes and small airway dilation; coarsely granular deposits along the basement membrane are found by electron beam scanning microscopy [159]. Under polarised light, the protein deposits do not show the apple-green birefringence on Congo red staining as occurs in amyloidosis [160]. Although the mechanisms for cyst formation in LCDD are still not completely understood, increased MMP activity has been suggested by Colombat et al. [7]. Pulmonary LCDD is a progressive disease that can cause respiratory failure. Therapy is based on treatment of the underlying haematological disease, if present; lung transplantation has to be considered for end-stage respiratory failure [160]. A retrospective study on lung transplantation in a small series of seven patients with LCDD reported three deaths; the Kaplan-Meier survival was $85.7 \%, 85.7 \%$, and $64.3 \%$ at 1-, 3- and 5 -year intervals, respectively. No evidence of recurrence of the disease was found at the end of the follow-up period [161].

Amyloidosis is a rare and heterogeneous group of disorders characterised by the extracellular deposition of a specific protein, known as amyloid, in an abnormal fibrillary fashion. Amyloidosis usually occurs as a systemic disease, but it can show localised organ involvement in some patients. CT findings in pulmonary involvement include multiple nodules, that may be cavitary lesions, parenchymal infiltrates, thickening of the tracheal wall and lymphadenopathy $[162,163]$. Cystic changes are a rare manifestation of pulmonary amyloidosis, sometimes in association with Sjögren syndrome or MALT lymphoma [164-166]. On HRCT, the cysts are usually thin-walled and are found in the periphery of the lungs; in Sjögren syndrome multiple nodules abutting the walls of the cysts may also be present [167]. The histological diagnosis is based on the finding of fibrillar deposits showing the typical apple-green birefringence on Congo red staining [160]. To date, no established curative therapy is available [168].

\section{Congenital lung disease associated to aberrant lung development and growth}

Among ultra-rare cystic diseases affecting the lung, mostly in children [169] and more rarely in adults [170], a broad spectrum of abnormalities is represented by congenital pulmonary airway malformations (CPAMs), previously called congenital cystic adenomatoid malformations. 
The mechanisms of the embryogenic insult and its timing is not clear, but it is supposed to occur from the 5 th to the 22nd week of gestation $[171,172]$. Several microscopic features help to distinguish CPAM from other lesions and/or normal lung, such as the presence of mucosal polypoid projection, an increased smooth muscle layer associated with the presence of elastic tissue within cyst walls, the absence of cartilage within the mass along with the presence of mucous-secreting cells without the presence of inflammatory cells.

CPAMs have been divided into three different groups according to the size and localisation of the cysts as well as other associated congenital abnormalities. The most frequent kind, especially among adults, is type 1. This shows the presence of multiple cysts with a diameter $\geqslant 2 \mathrm{~cm}$, appearing as a large, air-filled multicystic lesion on a CT scan. Type 2 consists of multiple cysts $<2 \mathrm{~cm}$, while in type 3 , there are several mini cysts, with a solid appearance on CT. As the last type has a worse prognosis, it is rare in adults and it is therefore the least commonly observed [173].

The most frequent cause of CPAM in children is bronchopulmonary dysplasia, which is a chronic lung disease caused by disruption in distal lung growth in association with barotrauma induced by ventilation in premature newborns. Cystic lesions can be observed in the first few days after birth and are generally bilateral; however, its clinical manifestation can be asymptomatic and lesions are occasionally diagnosed in young adults [174]. Other rare cystic congenital manifestations are lobar emphysema, congenital bulla, congenital bronchiectasis and bronchial atresia.

Symptoms are not specific and chest radiography is the first examination recommended. If performed in the neonatal period, it may show retained fetal lung fluid within the CPAM. Microcystic lesions do not change with time, while macrocystic CPAMs tends to become aerated after mechanical ventilation and the cysts appear to be air-filled. The differential diagnosis, based on imaging findings, includes congenital diaphragmatic hernia, particularly when the left hemithorax is involved. The diagnosis may be based on specific characteristics such as the position of the orogastric tube within the intra-thoracic portion of the stomach or the herniation of bowel loops into the chest demonstrated by contrast studies. Mediastinal displacement, compression of adjacent normal lung and flattening of the intact ipsilateral diaphragm represent other CPAM indirect features. However, these lesions are often not detected by chest radiograph, even when clearly observed at the ultrasound prenatal screening; a CT scan or MRI should be considered.

Surgical resection is the most recommended approach, so far. Generally, lobectomy is required for the complete resection of the lesion, but in selected cases segmental resection might be the resolution. Pneumectomy is indicated only in the rare event of multilobar involvement [173].

Due to CPAMs' anomalous connection to the tracheobronchial tree, patients are at high risk of infection and recurrent pneumonia. Furthermore, the development of malignancies, such as myxosarcoma, embryonal rhabdomyosarcoma, pleuropulmonary blastoma, and bronchoalveolar carcinoma have been reported [174-177]. However, the increased utilisation of routine ultrasound screening allows a large number of prenatal diagnosis in the second trimester as this is a reliable and accurate diagnostic tool in detecting echogenic pulmonary lesions [178]. In the presence of large cysts, a close ultrasound follow-up is mandatory due to the high risk of hydrops connected to this condition. In these cases, the use of steroids is indicated in order to reduce the volume of the cyst or, in nonresponders, fetal surgery could be a treatment option $[179,180]$.

\section{Cystic lung disease associated with neoplastic lesions}

The development of multiple pulmonary cysts as a result of a malignant condition is very rare and is generally secondary to a metastatic spread from peripheral sarcomas and mesenchymal tumours. Their pathogenic mechanism is still unclear.

The presence of excavated metastatic nodules, neoplastic cells within the walls of air spaces causing a ball-valve effect and of blood-filled cysts, in the case of angiosarcomas, are hypothesised mechanisms. Pneumothorax may be secondary to a direct tumour growth into the pleura or to the spread of cystic tumour lesions into the pleural space [181].

Pneumothorax is the clinical sign of the pulmonary manifestation of an extra-thoracic sarcoma, especially of the scalp [182]. Cystic or cavitary lesions, detected by chest radiography, have been found in 38 out of 153 patients with pneumothorax and sarcoma of different cell types.

Multiple thin-walled cysts have been detected at CT in five patients with metastatic pulmonary angiosarcoma. All five patients had pneumothorax and the follow-up CT scans showed an increase in cyst size and wall thickness [183]. Among adults, cystic lesions have also been reported in primary pulmonary neoplasms, such as bronchioalveolar cell carcinoma, mesenchymal cystic hamartoma, pleuropulmonary blastoma and lymphoma. In children, pleuropulmonary blastoma is a rare primary paediatric lung neoplasm, generally affecting children aged $<6$ years. Pleuropulmonary blastoma has been classified into 
three groups, according to the type of pulmonary lesions: type I is a multilocular cystic neoplasia, type II is a mix of solid and cystic tumour and type III a purely solid, high-grade sarcoma [184].

\section{Conclusions}

Among ultra-rare cystic lung diseases, LAM and PLCH are the most common disorders. In recent decades, the increasing recognition of CT patterns, of clinical manifestations and the identification of new biomarkers (e.g. serum VEGF-D in LAM), has allowed us to establish a correct diagnosis in a larger number of cases, leading to timely and early therapeutic intervention.

The identification of a cystic pattern at CT, should lead the clinician to consider other rare diseases, including autoimmune and congenital conditions, malignancies and immunodeficiencies. In these cases, in addition to radiological findings, the pathological features, the presence of genetic mutations and concomitant diseases should also be considered in the diagnostic process.

Conflict of interest: D. Elia has nothing to disclose. O. Torre has nothing to disclose. R. Cassandro has nothing to disclose. A. Caminati reports personal fees from Roche and Boehringer Ingelheim, outside the submitted work. S. Harari reports grants and personal fees from Roche, Actelion and Boehringer Ingelheim, outside the submitted work.

\section{References}

1 Hansel DM, Bankier AA, MacMahon H, et al. Fleishner Society: glossary of terms for thoracic imaging. Radiology 2008; 246: 697-722.

2 Torre O, Elia D, Caminati A, et al. New insight in lymphangioleiomyomatosis and pulmonary Langerhans cell histiocytosis. Eur Respir Rev 2017; 26: 170042.

3 Dines DE. Diagnostic significance of pneumatocele of the lung. JAMA 1968; 204: 1169-1172.

$4 \quad$ Kikuchi E, Kinoshhita I, Itoh T, et al. Epithelioid sarcoma presenting as pulmonary cysts with cancer antigen 125 expression. Respirology 2006; 11: 826-829.

5 Lee KH, Lee JS, Lynch DA, et al. The radiological differential diagnosis of diffuse lung diseases characterized by multiple cysts or cavities. J Comput Assist Tomogr 2002; 26: 5-12.

6 Ohdama S, Akagawa S, Matsubara O, et al. Primary diffuse alveolar septal amyloidosis with multiple cysts and calcification. Eurn Respir J 1996; 9: 1569-1571.

7 Colombat M, Caudroy S, Lagonotte E, et al. Pathomechanisms of cyst formation in pulmonary light chain deposition disease. Eur Respir J 2008; 32: 1399-1403.

$8 \quad$ Ryu JH, Tian X, Baqir M, et al. Diffuse cystic lung diseases. Front Med 2013; 7: 316-327.

9 Gupta N, Vassallo R, Wikenheiser-Brokamp KA, et al. Diffuse cystic lung disease. Part I. Am J Resp crit care med 2015; 191: 1354-1366.

10 Regulation (EU) No 536/2014 of the European Parliament and of the Council of 16 April 2014 on clinical trials on medicinal products for human use, and repealing Directive 2001/20/ EC. https://ec.europa.eu/health/sites/ health/files/files/eudralex/vol-1/reg_2014_536/reg_2014_536_en.pdf

11 Harari S, Torre O, Moss J. Lymphangioleiomyomatosis: what do we know and what are we looking for? Eur Respir Rev 2011; 20: 34-44.

12 Franz DN, Brody A, Meyer C, et al. Mutational and radiographic analysis of pulmonary disease consistent with lymphangioleiomyomatosis and micronodular pneumocyte hyperplasia in women with tuberous sclerosis. Am J Respir Crit Care Med 2001; 164: 661-666.

13 Carsillo T, Astrinidis A, Henske EP. Mutations in the tuberous sclerosis complex gene TSC2 are a cause of sporadic pulmonary lymphangioleiomyomatosis. Proc Natl Acad Sci USA 2000; 97: 6085-6090.

$14 \mathrm{Yu} \mathrm{J}$, Astrinidis A, Henske EP. Chromosome 16 loss of heterozygosity in tuberous sclerosis and sporadic lymphangiomyomatosis. Am J Respir Crit Care Med 2001; 164: 1537-1540.

15 Ryu JH, Doerr CH, Fisher SD, et al. Chylothorax in lymphangioleiomyomatosis. Chest 2003; 123: 623-627.

16 Ryu JH, Moss J, Beck GJ, et al. The NHLBI lymphangioleiomyomatosis registry: characteristics of 230 patients at enrollment. Am J Respir Crit Care Med 2006; 173: 105-111.

17 Almoosa KF, Ryu JH, Mendez J, et al. Management of pneumothorax in lymphangioleiomyomatosis: effects on recurrence and lung transplantation complications. Chest 2006; 129: 1274-1281.

18 Taveira-DaSilva AM, Stylianou MP, Hedin CJ, et al. Maximal oxygen uptake and severity of disease in lymphangioleiomyomatosis. Am J Respir Crit Care Med 2003; 168: 1427-1431.

19 Hayashida M, Seyama K, Inoue Y, et al. The epidemiology of lymphangioleiomyomatosis in Japan: a nationwide cross-sectional study of presenting features and prognostic factors. Respirology 2007; 12: 523-530.

20 Taveira-DaSilva AM, Steagall WK, Rabel A, et al. Reversible airflow obstruction in lymphangioleiomyomatosis. Chest 2009; 136: 1596-1603.

21 Taveira-Dasilva AM, Stylianou MP, Hedin CJ, et al. Decline in lung function in patients with lymphangioleiomyomatosis treated with or without progesterone. Chest 2004; 126: 1867-1874.

22 Avila NA, Kelly JA, Dwyer AJ, et al. Lymphangioleiomyomatosis: correlation of qualitative and quantitative thin-section CT with pulmonary function tests and assessment of dependence on pleurodesis. Radiology 2002; 223: 189-197.

23 Paciocco G, Uslenghi E, Bianchi A, et al. Diffuse cystic lung diseases: correlation between radiologic and functional status. Chest 2004; 125: 135-142.

24 Urban T, Lazor R, Lacronique J, et al. Pulmonary lymphangioleiomyomatosis. A study of 69 patients. Groupe d'Etudes et de Recherche sur les Maladies "Orphelines" Pulmonaires (GERM“O”P). Medicine (Baltimore) 1999; 78: 321-337.

25 Johnson SR, Tattersfield A. Decline in lung function in lymphangioleiomyomatosis: relation to menopause and progesterone treatment. Am J Respir Crit Care Med 1999; 160: 628-633. 
Baldi BG, Freitas CS, Araujo MS, et al. Clinical course and characterisation of lymphangioleiomyomatosis in a Brazilian reference centre. Sarcoidosis Vasc Diffuse Lung Dis 2014; 31: 129-135.

McCormack FX, Inoue Y, Moss J, et al. Efficacy and safety of sirolimus in lymphangioleiomyomatosis. $N$ Engl J Med 2011; 364: 1595-1606.

Chang WYC, Cane JL, Kumaran M, et al. A 2-year randomised placebo-controlled trial of doxycycline for lymphangioleiomyomatosis. Eur Respir J 2014; 43: 1114-1123.

Johnson SR, Whale CI, Hubbard RB, et al. Survival and disease progression in UK patients with lymphangioleiomyomatosis. Thorax 2004; 59: 800-803.

Avila NA, Kelly JA, Chu SC, et al. Lymphangioleiomyomatosis: abdominopelvic CT and US findings. Radiology 2000; 216: 147-153.

Cudzilo CJ, Szczesniak RD, Brody AS, et al. Lymphangioleiomyomatosis screening in women with tuberous sclerosis. Chest 2013; 144: 578-585.

Yeoh ZW, Navaratnam V, Bhatt R, et al. Natural history of angiomyolipoma in lymphangioleiomyomatosis: implications for screening and surveillance. Orphanet J Rare Dis 2014; 9: 151

Rakowski SK, Winterkorn EB, Paul E, et al. Renal manifestations of tuberous sclerosis complex: incidence, prognosis, and predictive factors. Kidney Int 2006; 70: 1777-1782.

Nelson CP, Sanda MG. Contemporary diagnosis and management of renal angiomyolipoma. J Urol 2002; 168: 1315-1325.

Helenon O, Merran S, Paraf F, et al. Unusual fat-containing tumors of the kidney: a diagnostic dilemma. Radiographics 1997; 17: 129-144.

Johnson SR, Tattersfield AE. Clinical experience of lymphangioleiomyomatosis in the UK. Thorax 2000; 55: 1052-1057.

Lu HC, Wang J, Tsang YM, et al. Lymphangioleiomyomatosis initially presenting with abdominal pain: a case report. Clin Imaging 2003; 27: 166-170.

Wong YY, Yeung TK, Chu WCW. Atypical presentation of lymphangioleiomyomatosis as acute abdomen: CT diagnosis. AJR Am J Roentgenol 2003; 181: 284-285.

Merchant RN, Pearson MG, Rankin RN, et al. Computerized tomography in the diagnosis of lymphangioleiomyomatosis. Am Rev Respir Dis 1985; 131: 295-297.

Johnson SR, Cordier JF, Lazor R, et al. European Respiratory Society guidelines for the diagnosis and management of lymphangioleiomyomatosis. Eur Respir J 2010; 35: 14-26.

Seyama K, Kumasaka T, Souma S, et al. Vascular endothelial growth factor-D is increased in serum of patients with lymphangioleiomyomatosis. Lymphat Res Biol 2006; 4: 143-152.

Glasgow CG, Avila NA, Lin JP, et al. Serum vascular endothelial growth factor-D levels in patients with lymphangioleiomyomatosis reflect lymphatic involvement. Chest 2009; 135: 1293-1300.

Engl J Med 2008; 358: 199-200.

Young LR, Vandyke R, Gulleman PM, et al. Serum vascular endothelial growth factor-D prospectively distinguishes lymphangioleiomyomatosis from other diseases. Chest 2010; 138: 674-681.

Radzikowska E, Jaguś P, Skoczylas A, et al. Role of serum vascular endothelial growth factor D in discrimination of patients with polycystic lung diseases. Pol Arch Med Wewn 2013; 123: 533-538.

McCormack FX, Gupta N, Finlay GR, et al. Official American Thoracic Society/Japanese Respiratory Society Clinical Practice Guidelines: lymphangioleiomyomatosis diagnosis and management. Am J Respir Crit Care Med 2016; 194: 748-761.

Gupta N, Finlay GA, Kotloff MR, et al. Official American Thoracic Society/Japanese Respiratory Society Clinical Practice Guidelines: lymphangioleiomyomatosis diagnosis and management. Am J Respir Crit Care Med 2017; 196: $1337-1348$.

Harari S, Torre O, Cassandro $\mathrm{R}$, et al. Bronchoscopic diagnosis of Langerhans cell histiocytosis and lymphangioleiomyomatosis. Respir Med 2012; 106: 1286-1292.

Pacheco-Rodriguez G, Steagall WK, Crooks DM, et al. TSC2 loss in lymphangioleiomyomatosis cells correlated with expression of CD44v6, a molecular determinant of metastasis. Cancer Res 2007; 67: 10573-10581.

Young L, Lee HS, Inoue Y, et al. Serum VEGF-D a concentration as a biomarker of lymphangioleiomyomatosis severity and treatment response: a prospective analysis of the Multicenter International Lymphangioleiomyomatosis Efficacy of Sirolimus (MILES) trial. Lancet Respir Med 2013; 1: 445-452.

Radzikowska E, Jaguś P, Sobiecka M, et al. Correlation of serum vascular endothelial growth factor-D concentration with clinical presentation and course of lymphangioleiomyomatosis. Respir Med 2015; 109: 1469-1475.

Taveira-DaSilva AM, Jones AM, Julien-Williams P, et al. Long-term effect of sirolimus on serum vascular endothelial growth factor D levels in patients with lymphangioleiomyomatosis. Chest 2018; 153: 124-132. histologic score. Am J Surg Pathol 2001; 25: 479-484.

Oprescu N, McCormack FX, Byrnes S, et al. Clinical predictors of mortality and cause of death in lymphangioleiomyomatosis: a population-based registry. Lung 2013; 191: 35-42.

Gupta N, Lee HS, Ryu JH, et al. The NHLBI LAM registry: prognostic physiologic and radiologic biomarkers emerge from a 15-year prospective longitudinal analysis. Chest 2019; 155: 288-296.

Bissler JJ, McCormack FX, Young LR, et al. Sirolimus for angiomyolipoma in tuberous sclerosis complex or lymphangioleiomyomatosis. N Engl J Med 2008; 358: 140-151.

Taveira-DaSilva AM, Hathaway O, Stylianou M, et al. Changes in lung function and chylous effusions in patients with lymphangioleiomyomatosis treated with sirolimus. Ann Intern Med 2011; 154: 797-805.

Moua T, Olson EJ, Jean HC, et al. Resolution of chylous pulmonary congestion and respiratory failure in lymphangioleiomyomatosis with sirolimus therapy. Am J Respir Crit Care Med 2012; 186: 389-390.

Harari S, Elia D, Torre O, et al. Sirolimus therapy for patients with lymphangioleiomyomatosis leads to loss of chylous ascites and circulating LAM cells. Chest 2016; 150: e29-e32.

Bee J, Fuller S, Miller S, et al. Lung function response and side effects to rapamycin for lymphangioleiomyomatosis: a prospective national cohort study. Thorax 2018; 73: 369-375. 
61 Taylor JR, Ryu J, Colby TV, et al. Lymphangioleiomyomatosis. Clinical course in 32 patients. N Engl J Med 1990; 323: 1254-1260.

62 Eliasson AH, Phillips YY, Tenholder MF. Treatment of lymphangioleiomyomatosis: a meta-analysis. Chest 1989; 96: 1352-1355.

63 Medeiros P, Kairalla RA, Pereira CAC, et al. GnRH analogs X progesterone-lung function evolution in two treatment cohort groups in lymphangioleiomyomatosis (LAM). Am J Respir Crit Care Med 2003; 167: A953.

64 de la Fuente J, Páramo C, Román F, et al. Lymphangioleiomyomatosis: unsuccessful treatment with luteinizing-hormone-releasing hormone analogues. Eur J Med 1993; 2: 377-378.

65 Harari S, Cassandro R, Chiodini I, et al. Effect of a gonadotrophin-releasing hormone analogue on lung function in lymphangioleiomyomatosis. Chest 2008; 133: 448-454.

66 Lu C, Lee HS, Pappas GP, et al. A Phase II clinical trial of an aromatase inhibitor for postmenopausal women with lymphangioleiomyomatosis. Ann Am Thorac Soc 2017; 14: 919-928.

67 Moses MA, Harper J, Folkman J. Doxycycline treatment for lymphangioleiomyomatosis with urinary monitoring for MMPs. N Engl J Med 2006; 324: 2621-2622.

68 Parkhitko A, Myachina F, Morrison TA, et al. Tumorigenesis in tuberous sclerosis complex is autophagy and p62/sequestosome 1 (SQSTM1)-dependent. Proc Natl Acad Sci USA 2011; 108: 12455-12460.

69 El-Chemaly S, Taveira-Dasilva A, Goldberg HJ, et al. Sirolimus and autophagy inhibition in lymphangioleiomyomatosis: results of a phase I clinical trial. Chest 2017; 151: 1302-1310.

70 Khawar MU, Yazdani D, Zhu Z, et al. Clinical outcomes and survival following lung transplantation in patients with lymphangioleiomyomatosis. J Heart Lung Transplant 2019; 38: 949-955.

71 Salman J, Ius F, Sommer W, et al. Long-term results of bilateral lung transplantation in patients with end-stage pulmonary lymphangioleiomyomatosis. Prog Transplant 2019; 29: 115-121.

72 Kurosaki T, Otani S, Miyoshi K, et al. Favorable survival even with high disease-specific complication rates in lymphangioleiomyomatosis after lung transplantation-long-term follow-up of a Japanese center. Clin Respir J 2020; 14: 116-123.

73 Hsu TH, O’Hara J, Mehta A, et al. Nephron-sparing nephrectomy for giant renal angiomyolipoma associated with lymphangioleiomyomatosis. Urology 2002; 59: 138. Writing Group of the Histiocyte Society. Histiocytosis syndromes in children. Lancet 1987; 1: 208-209.

Emile JF, Abla O, Fraitag S, et al. Revised classification of histiocytosis and neoplasms of the macrophage-dendritic cell lineages. Blood 2016; 22: 2672-2681.

76 Hervier B, Haroche J, Arnaud L, et al. Association of both Langerhans cell histiocytosis and Erdheim-Chester disease linked to the BRAF V600E mutation. Blood 2014; 124: 1119-1126.

77 Badalian-Very G, Vergilio JA, Degar BA, et al. Recurrent BRAF mutations in Langerhans cell histiocytosis. Blood 2010; 116: 1919-1923.

78 Haroche J, Charlotte F, Arnaud L, et al. High prevalence of BRAF V600E mutations in Erdheim-Chester disease but not in other non-Langerhans cell histiocytosis. Blood 2012; 120: 2700-2703.

79 Emile JF, Diamond EL, Helias-Rodzewicz Z, et al. Recurrent RAS and PIK3CA mutations in Erdheim-Chester disease. Blood 2014; 124: 3016-3019.

80 Diamond EL, Durham BH, Haroche J, et al. Diverse and targetable kinase alterations drive histiocytic neoplasms. Cancer Discov 2016; 6: 154-116.

81 Berres ML, Lim KP, Peters T, et al. BRAF V600E expression in precursor versus differentiated dendritic cells defines clinically distinct LCH risk groups. J Exp Med 2014; 211: 669-683.

82 Milne P, Bigley V, Bacon CM, et al. Haematopoietic origin of Langerhans cell histiocytosis and Erdheim-Chester disease in adults. Blood 2017; 130: 167-175.

83 Durham BH, Roos-Weil D, Baillow C, et al. Functional evidence for derivation of systemic histiocytic neoplasms from haematopoietic stem/progenitor cells. Blood 2017; 130: 176-180.

84 Vassallo R, Harari S, Tazi A. Current understanding and management of pulmonary Langerhans cell histiocytosis. Thorax 2017; 72: 937-945.

85 Haupt R, Minkov M, Astigarraga I, et al. Langerhans cell histiocytosis: guidelines for diagnosis, clinical workup and treatment for patients till the age of 18 years. Paediatr Blood Cancer 2013; 60: 175-184.

86 Diamond EL, Degna L, Hyman D, et al. Consensus guidelines for the diagnosis and clinical management of Erdheim-Chester disease. Blood 2014; 124: 483-492.

87 Arico M, Girschikofsky M, Genereau T, et al. Langerhans cell histiocytosis in adults: report from the International Registry of the Histiocyte Society. Eur J Cancer 2003; 39: 2341-2348.

88 Haroche J, Arnaud L, Cohen-Aubart F, et al. Erdheim-Chester disease. Rheum Dis Clin North Am 2013; 39: 299-311.

89 Arnaud L, Pierre I, Beigelman-Aubry C, et al. Pulmonary involvement in Erdheim-Chester disease: a single-center study of thirty-four patients and a review of the literature. Arthritis Rheum 2010; 62: 3504-3512.

90 Karcioglu ZA, Shaara N, Boles T. Orbital xanthogranuloma: clinical and morphologic features in eight patients. Ophtal Plast Reconstr Surg 2003; 19: 372-381.

91 Brauner MW, Grenier P, Tijani K, et al. Pulmonary Langerhans cell histiocytosis: evolution of lesions on CT scans. Radiology 1997; 204: 497-502.

92 Vassallo R, Jensen EA, Colby TV, et al. The overlap between respiratory bronchiolitis and desquamative interstitial pneumonia in pulmonary Langerhans cell histiocytosis: high-resolution CT, histologic, and functional correlations. Chest 2003; 124: 1199-1205.

93 Rush WL, Andriko JAW, Galateau-Salle F, et al. Pulmonary pathology of Erdheim-Chester disease. Mod Pathol 2000; 13: 747-754.

94 Kambouchner M, Colby TV, Domenage JP, et al. Erdheim-Chester disease with prominent pulmonary involvement associated with eosinophilic granuloma of mandibular bone. Histopathology 1997; 30: 353-358.

95 Danel C, Israel-Biet D, Costabel U, et al. The clinical role of BAL in pulmonary histiocytosis X. Eur Respir J 1990; 3: 94961-94969.

96 Fruchter O, Fridel L, El Raouf BA, et al. Histological diagnosis of interstitial lung diseases by cryo-transbronchial biopsy. Respirology 2014; 19: 683-688.

97 Harari S, Cereda F, Pane F, et al. Lung cryobiopsy for the diagnosis of interstitial lung diseases: a series contribution to a debated procedure. Medicina (Kaunaus) 2019; 55: 606. 
Roden AC, Yi ES. Pulmonary Langerhans cell histiocytosis: an update from the pathologists' perspective. Arch Pathol Lab Med 2016; 140: 230-240.

99 Mourah S, How-Kit A, Meignin V, et al. Recurrent NRAS mutations in pulmonary Langerhans cell histiocytosis Eur Respir J 2016; 47: 1785-1796.

100 Wolters PJ, Elicker BM. Subacute onset of pulmonary Langerhans cell histiocytosis with resolution after smoking cessation. Am J Respir Crit Care Med 2014; 190: e64.

101 Tazi A, De Margerie C, Naccache JM, et al. The natural history of adult pulmonary Langerhans cell histiocytosis: a prospective multicentre study. Orphanet J Rare Dis 2015; 10: 30.

102 Grobost V, Khouatra C, Lazor R, et al. Effectiveness of cladribine therapy in patients with pulmonary Langerhans cell histiocytosis. Orphanet J Rare Dis 2014; 9: 191.

103 Pardanani A, Phyliky RL, Li CY, et al. 2-Chlorodeoxyadenosine therapy for disseminated Langerhans cell histiocytosis. Mayo Clin Proc 2003; 78: 301-306.

104 Lorillon G, Bergeron A, Detourmignies L, et al. Cladribine is effective against cystic pulmonary Langerhans cell histiocytosis. Am J Respir Crit Care Med 2012; 186: 930-932.

105 Goyal G, Shah MV, Call TG, et al. Clinical and radiologic responses to cladribine for the treatment of ErdheimChester disease. JAMA Oncol 2017; 3: 1253-1256.

106 Braiteh F, Boxrud C, Esmaeli B, et al. Successful treatment of Erdheim-Chester disease, a non-Langerhans cell histiocytosis, with interferon-alpha. Blood 2005; 106: 2992-2994.

107 Esmaeli B, Ahmadi A, Tang R, et al. Interferon therapy for orbital infiltration secondary to Erdheim-Chester disease. Am J Ophthalmol 2001; 132: 945-947.

108 Suzuki HI, Hosoya N, Miyagawa K, et al. Erdheim-Chester disease: multisystem involvement and management with interferon-alpha. Leuk Res 2010; 34: e21-e24.

109 Diamond EL, Subbiah V, Lockhart AC, et al. Vemurafenib for BRAF V600-mutant Erdheim-Chester disease and Langerhans cell histiocytosis: analysis of data from the histology independent, phase 2, open-label VE-BASKET study. JAMA Oncol 2018; 4: 384-388.

110 Haroche J, Cohen-Aubart F, Emile JF, et al. Dramatic efficacy of vemurafenib in both multisystemic and refractory Erdheim-Chester disease and Langerhans cell histiocytosis harboring the BRAF V600E mutation. Blood 2013; 121: 1495-1500.

111 Lorillon G, Jouenne F, Baroudjian B, et al. Response to trametinib of a pulmonary Langerhans cells histiocytosis harbouring a MAP2K1 deletion. Am J Resp Crit Care Med 2018; 198: 675-678.

112 Diamond EL, Durham BH, Ulaner GA, et al. Efficacy of MEK inhibition in patients with histiocytic neoplasms. Nature 2019; 567: 521-524.

113 Dauriat G, Mal H, Thabut G, et al. Lung transplantation for pulmonary Langerhans cell histiocytosis: a multicenter analysis. Transplantation 2006: 81746-81750.

114 Harari S, Simmoneau G, De Juli E, et al. Prognostic value of pulmonary hypertension in patients with chronic interstitial lung diseases referred for lung or heart-lung transplantation. Journ Heart Lung Transplant 1997; 16: 460-463.

115 Harari S, Brenot F, Barberis M, et al. Advanced pulmonary histiocytosis x is associated with severe pulmonary hypertension. Chest 1997; 111: 1142-1143.

116 Chaowalit N, Pellikka PA, Decker PA, et al. Echocardiographic and clinical characteristics of pulmonary hypertension complicating pulmonary Langerhans cell histiocytosis. Mayo Clin Proc 2004; 79: 1269-1275.

117 Le Pavec J, Lorillon G, Jaiis X, et al. Pulmonary Langerhans cell histiocytosis-associated pulmonary hypertension: clinical characteristics and impact of pulmonary arterial hypertension therapies. Chest 2012; 142: 1150-1157.

118 Adley BP, Smith ND, Nayar R, et al. Birt-Hogg-Dubé syndrome: clinicopathologic findings and genetic alterations. Arch Pathol Lab Med 2006; 130: 1865-1870.

119 Baba M, Hong SB, Sharma N, et al. Folliculin encoded by the BHD gene interacts with a binding protein, FNIP1, and AMPK, and is involved in AMPK and mTOR signaling. Proc Natl Acad Sci USA 2006; 103: 15552-15557.

120 Kumasaka T, Hayashi T, Mitani K, et al. Characterization of pulmonary cysts in Birt-Hogg-Dubé syndrome: histopathological and morphometric analysis of 229 pulmonary cysts from 50 unrelated patients. Histopathology 2014; 65: 100-110.

121 Hartman TR, Nicolas E, Klein-Szanto A, et al. The role of the Birt-Hogg-Dubé protein in mTOR activation and renal tumorigenesis. Oncogene 2009; 28: 1594-1604.

122 Hong SB, Oh H, Valera VA, et al. Tumor suppressor FLCN inhibits tumorigenesis of a FLCN-null renal cancer cell line and regulates expression of key molecules in TGF-beta signaling. Mol Cancer 2010; 9: 160.

123 Nookala RK, Langemeyer L, Pacitto A, et al. Crystal structure of folliculin reveals a hidDENN function in genetically inherited renal cancer. Open Biol 2012; 2: 120071.

124 Kennedy JC, Khabibullin D, Hougard T, et al. Loss of FLCN inhibits canonical WNT signaling via TFE3. Hum Mol Genet 2019; 28: 3270-3281.

125 Gupta N, Seyama K, McCormack FX. Pulmonary manifestations of Birt-Hogg-Dubé syndrome. Fam Cancer 2013; 12: 387-396.

126 Kunogi M, Kurihara M, Ikegami TS, et al. Clinical and genetic spectrum of Birt-Hogg-Dubé syndrome patients in whom pneumothorax and/or multiple lung cysts are the presenting feature. J Med Genet 2010; 47: $281-287$.

127 Gunji Y, Akiyoshi T, Sato T, et al. Mutations of the Birt-Hogg-Dubé gene in patients with multiple lung cysts and recurrent pneumothorax. J Med Genet 2007; 44: 588-593.

128 Tomassetti S, Carloni A, Chilosi M, et al. Pulmonary features of Birt-Hogg-Dubé syndrome: cystic lesions and pulmonary histiocytoma. Respir Med 2011; 105: 768-774.

129 Toro JR, Pautler SE, Stewart L, et al. Lung cysts, spontaneous pneumothorax, and genetic associations in 89 families with Birt-Hogg-Dubé syndrome. Am J Respir Crit Care Med 2007; 175: 1044-1053.

130 Escuissato DL, de Almeida Teixeira BC, Warszwiak D, et al. Renal tumor associated with pulmonary cysts: BirtHogg-Dubé syndrome. QJM 2014; 107: 851-852.

131 Zbar B, Alvord WG, Glenn G, et al. Risk of renal and colonic neoplasms and spontaneous pneumothorax in the Birt-Hogg-Dubé syndrome. Cancer Epidemiol Biomarkers Prev 2002; 11: 393-400.

132 Liu Y, Xing H, Huang Y, et al. Familial spontaneous pneumothorax: importance of screening for Birt-HoggDubé syndrome. Eur J Cardiothorac Surg 2019: 57: 39-45. 
Onuki T, Goto Y, Kuramochi M, et al. Radiologically indeterminate pulmonary cysts in Birt-Hogg-Dube syndrome. Ann Thorac Surg 2014; 97: 682-685.

Torricelli E, Occhipinti M, Cavigli E, et al. The relevance of family history taking in the detection and management of Birt-Hogg-Dubé syndrome. Respiration 2019; 98: 125-132.

Tobino K, Hirai $\mathrm{T}$, Johkoh $\mathrm{T}$, et al. Differentiation between Birt-Hogg-Dubé syndrome and lymphangioleiomyomatosis: quantitative analysis of pulmonary cysts on computed tomography of the chest in 66 females. Eur J Radiol 2012; 81: 1340-1346.

Park HJ, Chae EJ, Do KH, et al. Differentiation between lymphangioleiomyomatosis and Birt-Hogg-Dubé syndrome: analysis of pulmonary cysts on CT images. AJR Am J Roentgenol 2019; 212: 766-772.

Furuya M, Tanaka R, Koga S, et al. Pulmonary cysts of Birt-Hogg-Dubé syndrome: a clinicopathologic and immunohistochemical study of 9 families. Am J Surg Pathol 2012; 36: 589-600.

Menko FH, van Steensel MA, Giraud S, et al. Birt-Hogg-Dubé syndrome: diagnosis and management. Lancet Oncol 2009; 10: 1199-1206.

Pavlovich CP, Walther MM, Eyler RA, et al. Renal tumors in the Birt-Hogg-Dubé syndrome. Am J Surg Pathol 2002; 26: 1542-1552.

Pavlovich CP, Grubb RL III, Hurley K, et al. Evaluation and management of renal tumors in the Birt-HoggDubé syndrome. J Urol 2005; 173: 1482-1486.

Sattler EC, Reithmair M, Steinlein OK. Kidney cancer characteristics and genotype-phenotype-correlations in Birt-Hogg-Dubé syndrome. PLoS One 2018; 13: e0209504.

Stamatakis L, Metwalli AR, Middelton LA, et al. Diagnosis and management of BHD-associated kidney cancer. Fam Cancer 2013; 12: 397-402.

Tian X, Yi ES, Ryu JH. Lymphocytic interstitial pneumonia and other benign lymphoid disorders. Semin Respir Crit Care Med 2012; 33: 450-461.

Pathol Lab Med 2010; 134: 691-701.

Cha SI, Fessler MB, Cool CD, et al. Lymphoid interstitial pneumonia: clinical features, associations and prognosis. Eur Respir J 2006; 28: 364-369.

Gupta N, Vassallo R, Wikenheiser-Brokamp KA, et al. Diffuse cystic lung disease: part II. Am J Respir Crit Care Med 2015; 192: 17-29.

Kuo CW, Chang KC, Chang HY, et al. Lymphocytic interstitial pneumonia in a patient with a mixed connective tissue disease- A case report. Respir Med Case Rep 2018; 25: 12-17.

Johkoh T, Müller NL, Pickford HA, et al. Lymphocytic interstitial pneumonia: thin-section CT findings in 22 patients. Radiology 1999; 212: 567-572.

Honda $\mathrm{O}$, Johkoh $\mathrm{T}$, Ichikado $\mathrm{K}$, et al. Differential diagnosis of lymphocytic interstitial pneumonia and malignant lymphoma on high-resolution CT. AJR Am J Roentgenol 1999; 173: 71-74.

Watanabe M, Naniwa T, Hara M, et al. Pulmonary manifestations in Sjogren's syndrome: correlation analysis between chest computed tomographic findings and clinical subsets with poor prognosis in 80 patients. $J$ Rheumatol 2010; 37: 365-373.

Escalon JG, Richards JC, Koelsch T, et al. Isolated cystic lung disease: an algorithmic approach to distinguishing Birt-Hogg-Dubé syndrome, Lymphangioleiomyomatosis, and lymphocytic interstitial pneumonia. AJR Am J Roentgenol 2019, in press [https://doi.org/10.2214/AJR.18.20920].

Jawad H, Walker CM, Wu CC, et al. Cystic interstitial lung diseases: recognizing the common and uncommon entities. Curr Probl Diagn Radiol 2014; 43: 115-127.

Carrillo J, Restrepo CS, Rosado de Christenson $\mathrm{M}$, et al. Lymphoproliferative lung disorders: a radiologic-pathologic overview. Part I:reactive disorders. Semin Ultrasound CT MR 2013; 34: 525-534.

Barker AF, Bergeron A, Rom WN, et al. Obliterative bronchiolitis. N Engl J Med 2014; 370: 1820-1828.

Dufour V, Wislez M, Bergot E, et al. Improvement of symptomatic human immunodeficiency virus-related lymphoid interstitial pneumonia in patients receiving highly active antiretroviral therapy. Clin Infect Dis 2003; 36: e127-e130.

Johkoh T, Ichikado K, Akira M, et al. Lymphocytic interstitial pneumonia: follow-up CT findings in 14 patients. J Thorac Imaging 2000; 15: 162-167.

Richards JC, Lynch DA, Chung JH. Cystic and nodular lung disease. Clin Chest Med 2015; 36: 299-312.

Buxbaum J, Gallo G. Nonamyloidotic monoclonal immunoglobulin deposition disease: light-chain, heavy-chain, and light- and heavy-chain deposition diseases. Hematol Oncol Clin North Am 1999; 13: 1235-1248.

Am J Respir Crit Care Med 2006; 173: 777-780.

Randall RE, Williamson WC Jr, Mullinax F, et al. Manifestations of systemic light chain deposition. Am J Med 1976; 60: 293-299.

Hirschi S, Colombat M, Kessler R, et al. Lung transplantation for advanced cystic lung disease due to nonamyloid kappa light chain deposits. Ann Am Thorac Soc 2014; 11: 1025-1031.

Sakai M, Yamaoka M, Kawaguchi M, et al. Multiple cystic pulmonary amyloidosis. Ann Thorac Surg 2011; 92: e109.

Gertz MA, Dispenzieri A. Immunoglobulin light-chain amyloidosis: growing recognition, new approaches to therapy, active clinical trials. Oncology 2012; 26: 152-161.

Baqir M, Kluka EM, Aubry MC, et al. Amyloid-associated cystic lung disease in primary Sjögren's syndrome. Respir Med 2013; 107: 616-621.

Singapore Med J 2013; 54: e97-e99.

Lantuejoul S, Moulai N, Quetant S, et al. Unusual cystic presentation of pulmonary nodular amyloidosis associated with MALT-type lymphoma. Eur Respir J 2007; 30: 589-592.

67 Jeong YJ, Lee KS, Chung MP, et al. Amyloidosis and lymphoproliferative disease in Sjögren syndrome: thin-section computed tomography findings and histopathologic comparisons. J Comput Assist Tomogr 2004; 28: 776-781.

168 Ferreira Francisco FA, Soares Souza A Jr, Zanetti G, et al. Multiple cystic lung disease. Eur Respir Rev 2015; 24: $552-564$. 
Barman S, Mandal KC, Kumar R. Congenital cystic lesions of lung in the paediatric population: a 5-year single institutional study with review of literature. Afr J Paediatr Surg 2015; 12: 66-70.

170 Plit ML, Blott JA, Lakis N, et al. Clinical, radiographic and lung function features of diffuse congenital cystic adenomatoid manifestation of the lung in adult. Eur Respir J 1997; 10: 1680-1682.

171 Laberge JM, Flageole H, Pugash D, et al. Outcome of the prenatality diagnosed congenital cystic adenomatoid lung malformation: a Canadian experience. Fetal Diagno Ther 2001; 16: 178-186.

172 Wilson RD, Hedrick HL, Liechty KW, et al. Cystic adenomatoid malformation of the lung: review of genetics, prenatal diagnosis and in utero treatment. Am J Med Geneic A 2006; 140: 151-155.

173 Azizkhan RG, Crombleholme TM. Congenital cystic lung disease: contemporary antenatal and postnatal management. Pediatr Surg Int 2008; 24: 643-657.

174 Lim FY, Crombleholme TM, Hedrick HL, et al. Congenital high airway obstruction syndrome: natural history and management. J Pediatr Surg 2003; 38: 940-945.

175 Federici S, Domenichelli V, Tani G, et al. Pleuropulmonary blastoma in congenital cystic adenomatoid malformation: report of a case. Eur J Pediatr Surg 2001; 11: 196-199.

176 Picaud JC, Levrey H, Bouvier R, et al. Bilateral cystic pleuropulmonary blastoma in early infancy. J Pediatr 2000; 136: 834-836.

177 Sudou M, Sugi K, Murakami T. Bronchioloalveolar carcinoma arising from a congenital cystic adenomatoid malformation in an adolescent. The first case report from the orient. J Thorac Cardiovasc Surg 2003; 126: 902-903.

178 Adzick NS, Harrison MR, Crombleholme TM, et al. Fetal lung lesions: management and outcome. Am J Obstet Gynecol 1998; 179: 884-889.

179 Adzick NS, Harrison MR, Flake AW, et al. Fetal surgery for cystic adenomatoid malformations of the lung. $J$ Pediatr Surg 1993; 28: 806-812.

180 Taguchi T, Suita S, Yamanouchi T, et al. Antenatal diagnosis surgical management of congenital cystic adenomatoid malformation of the lung. Fetal Diagn Ther 1995; 10: 400-407.

181 Somasekharan Nair KK, Zabell AS, Vo KL, et al. Pneumothorax: a classical presentation of metastatic scalp angiosarcoma. Ann Thor Surg Pathol 2012; 94: e77-e78.

182 Hoag JB, Sherman M, Fasihuddin Q, et al. A comprehensive review of spontaneous pneumothorax complicating sarcoma. Chest 2010; 138: 510-518.

183 Tateishi U, Hasegawa T, Kusumoto M, et al. Metastatic angiosarcoma of the lung: spectrum of CT findings. AJR Am J Reontol 2003; 180: 1671-1674.

184 Ferrari A, Brecht IB, Gatta G, et al. Defining and listing very rare cancers of paediatric age: consensus of the Joint Action on Rare Cancers in cooperation with the European Cooperative Study Group for Pediatric Rare Tumors. Eur J Cancer 2019; 110: 120-126. 